\title{
An Undergraduate Experiment Using Microwave-Assisted Synthesis of First Raw Metalloporphyrins: Characterizations and Spectroscopic Study
}

\author{
Muna Bufaroosha*, Shaikha S. Al Neyadi, Mohamed A.R. Alnaqbi, \\ Sayed A.M. Marzouk, Abdullah Al-Hemyari, Bashar Yousef Abuhattab, Dana Akram Adi \\ Department of Chemistry, College of Science, UAE University, Al-Ain, UAE \\ *Corresponding author: muna.bufaroosha@uaeu.ac.ae
}

Received July 19, 2019; Revised August 21, 2019; Accepted September 20, 2019

\begin{abstract}
There is a notable absence in the practical inorganic curricula for experiments in which students can synthesize and characterize series of inorganic complexes. This is possibility attributed to the long required time which is not normally available in regular lab sessions. To address this absence, this paper describes a two-part experiment for chemistry major students in which they prepare series of metalloporphyrins using microwaveassisted technique. In addition to its attractive simplicity, microwave-assisted preparation substantially reduces the needed reaction time to suit the lab session duration. The first lab session is dedicated to the characterization of the 5,10,15,20-tetraphenylporphyrin (TPP) as well as the synthesis of the corresponding $\mathrm{Fe}(\mathrm{II}), \mathrm{Co}(\mathrm{II}), \mathrm{Ni}(\mathrm{II}), \mathrm{Cu}(\mathrm{II})$ and $\mathrm{Zn}(\mathrm{II})$ complexes. The second session involves the spectroscopic characterization (UV-vis, $1 \mathrm{H}$-NMR, and IR) of the prepared metalloprophyrins. The students relate the experimental results with the provided theoretical data based on quantum chemical calculations.
\end{abstract}

Keywords: Metalloporphyrins Frontiers Orbitals, metalloporphyrins electronic structure, metalloporphyrins microwave-assisted synthesis

Cite This Article: Muna Bufaroosha, Shaikha S. Al Neyadi, Mohamed A.R. Alnaqbi, Sayed A.M. Marzouk, Abdullah Al-Hemyari, Bashar Yousef Abuhattab, and Dana Akram Adi, "An Undergraduate Experiment Using Microwave-Assisted Synthesis of First Raw Metalloporphyrins: Characterizations and Spectroscopic Study." World Journal of Chemical Education, vol. 7, no. 3 (2019): 225-231. doi: 10.12691/wjce-7-3-6.

\section{Introduction}

Since metalloporphyrins play an essential role in the chemistry of the living entities [1,2,3], scientists have always found them fascinating to study, understand, and mimic. Therefore, synthetic metalloporphyrins possess substantial significance in our world. For example, to be capable of understanding the detailed biological reactions involved in enzymatic processes, we need biomimetic representatives of these complicated enzymatic molecules. Synthetic metalloporphyrins provide such biomimicry molecules; and nowadays, they play important roles in medicine [4] materials [5] catalyst [6] among others. In general, to demonstrate a relationship between the structures and certain properties in class of complexes, usually, it requires many experimental and quantum calculations studies. The time constraint in educational laboratories makes it difficult to introduce this kind of experiments at the undergraduate level. However, with the advances in microwave-assisted synthesis technique, it is possible to reduce the experimental time substantially.
This technique offers many advantages such as reduction in reaction time and increased product yield. [7]

In addition to the laboratory work, we provided results of quantum cautions for the series of the complexes in the experiment. To explain a chemical phenomenon by combining experimental results with computational data gives a great depth of comprehension of the studied phenomenon. Exposing undergraduate students to this type of experiments where interpreting theoretical findings are used to explain empirical data, raise their appreciation and understanding for theoretical and computational methods in chemistry and their usages. The two-session undergraduate laboratory experiments presented in this paper involves synthesis and spectroscopic analysis of the synthetic metallotetraphenylporphyrins of the first-row transition metal (II) ions: $\mathrm{Fe}, \mathrm{Co}, \mathrm{Ni}, \mathrm{Cu}$, and $\mathrm{Zn}$ which will be prepared using microwave technique. The synthesized complexes will be characterized via UV-visible spectra, ${ }^{1} \mathrm{H}$-NMR spectra, and infrared spectra. Because it is possible to conduct multi reactions at the same time in the multi-mode microwave providing that all the reaction requires the same conditions, therefore, it is achievable to prepare the whole series in the same time in 
one laboratory session. Thus, with the availability of Microwave of multi-reaction tubes, it is possible to divide the students into small groups (two to three students per group) and assign one complex for each group to synthesize and carry out all the spectral studies for it. In the first session, the students will be given pre-prepared 5,10,15,20-tetraphenylporphyrin (TPP). The $\mathrm{H}_{2} \mathrm{TPP}$ synthesis procedure is provided in the Supporting Information. The students will perform spectroscopically characterizations, $\mathrm{UV}$-vis, ${ }^{1} \mathrm{H}$-NMR, and IR, on the free base to confirm its structure. The following task will be carrying out the TPP metallization as described in the Supporting Information via microwave-assisted synthesis technique. The second session involves the synthesis and characterization of metal (II) ions complexes of (Fe (II), Co(II), Ni(II), Cu(II) and $\mathrm{Zn}(\mathrm{II})$ ) which are described in the Supporting Information. The students will be divided into five groups and each group will be responsible for the synthesis and characterizations of a specific complex. By the end of the two sessions, the students will acquire spectroscopic data for the five complexes. To explain these spectra, the students need to predict the structure of the complexes and their electron configurations. The students will notice that there are some differences between the predicted electron configurations and the resulted ${ }^{1} \mathrm{HMR}$. The quantum chemical calculations usually offer good predictions regarding the order of the frontiers orbitals of the molecules. Referring to these quantum calculations sometimes provides a good explanation for the experimental results.

\section{Materials and Methods}

\subsection{General}

All reagents and chemicals were purchased from Sigma-Aldrich and used as received. Benzaldehyde $\left(\mathrm{C}_{7} \mathrm{H}_{6} \mathrm{O}\right)$, pyrrole $\left(\mathrm{C}_{4} \mathrm{H}_{5} \mathrm{~N}\right)$, propionic acid $\left(\mathrm{CH}_{3} \mathrm{CH}_{2} \mathrm{COOH}\right)$, Zinc acetate dehydrate $\left(\mathrm{Zn}\left(\mathrm{CH}_{3} \mathrm{CO}_{2}\right)_{2} \cdot 2 \mathrm{H}_{2} \mathrm{O}\right)$, Nickel(II) acetate tetrahydrate $\left(\mathrm{Ni}\left(\mathrm{CH}_{3} \mathrm{CO}_{2}\right)_{2} \cdot 4 \mathrm{H}_{2} \mathrm{O}\right)$, iron (III) sulfate heptahydrate $\left(\mathrm{FeSO}_{4} \cdot 7 \mathrm{H}_{2} \mathrm{O}\right)$, Cobalt(II) chloride hexahydrate $\left(\mathrm{CoCl}_{2} \cdot 6 \mathrm{H}_{2} \mathrm{O}\right)$, Copper(II) nitrate trihydrate $\left(\mathrm{Cu}\left(\mathrm{NO}_{3}\right)_{2} .3 \mathrm{H}_{2} \mathrm{O}\right)$, chloroform- $d\left(\mathrm{CDCl}_{3}\right)$ were purchased from Sigma-Aldrich Chemical Company (Sigma Chemical Co., St. Louis, MO, USA). Thin-layer chromatography (TLC) was performed on silica gel glass plates (Silica gel, 60 F254, Fluka) and spots were visualized under UV lamp. Column chromatography was performed on Kieselgel S (Silica gel S, 0.063-0.1mm). Melting points recorded on a Gallenkamp apparatus and are uncorrected. Infrared spectra were measured using $\mathrm{KBr}$ pellets on a Thermo Nicolet model 470 FT-IR spectrophotometer. ${ }^{1} \mathrm{H}-\mathrm{NMR}$ spectra were recorded on Varian, $400 \mathrm{MHz}$ instruments by using DMSO-d6 and $\mathrm{CDCl}_{3}$ solutions and tetramethylsilane (TMS) as an internal reference. Microwave-assisted reactions performed using a microwave reactor (one touch technology CEM- Matthews, NC, USA). Multimode reactor is use for running a single vessel $(20 \mathrm{ml})$ or up to 40 in parallel. Absorption measurements were carried out using Agilent 8453 spectrophotometer supported with 1.0 cm quartz cells (Austria).

\subsection{Synthesis}

\subsubsection{Synthesis of Meso-tetraphenylporphyrin (TPP) 3}

A microwave vessel equipped with a standard cap (vessel commercially furnished by CEM Discover) was filled with $10 \mathrm{mmol}$ of Benzaldehyde and $10 \mathrm{mmol}$ of pyrrole. Then to this mixture propionic acid $(3.5 \mathrm{~mL})$ and nitrobenzene $(1.5 \mathrm{~mL})$ were added in the reaction vessel. After the vessel was sealed, the reaction mixture heated under microwave irradiation $\left(150^{\circ} \mathrm{C}\right)$ for $10 \mathrm{~min}$. The irradiation power was $600 \mathrm{~W}$. The progress of the reaction was monitored by TLC and after completion porphyrin was crystallized overnight from the concentrated crude product mixture by addition of methanol. The dark purple solid was then filtered off, washed with methanol, dried to give pure porphyrin in a good yield; dark purple solid;; yield 68\%; mp $300^{\circ} \mathrm{C}$; IR (KBr, $\left.\mathrm{cm}^{-1}\right)$ : $3314(\mathrm{NH}), 3052$ and 2923 (ArH), 1472 and 1440 (NH bending), 698 (out of plane bending deformation, monosubstituted benzene), $1593(\mathrm{C}=\mathrm{C}), 1490(\mathrm{C}=\mathrm{N}) ;{ }^{1} \mathrm{H}-\mathrm{NMR}\left(400 \mathrm{MHz}, \mathrm{CDCl}_{3}\right) \delta$ ppm: -2.74 (brs, $2 \mathrm{H},-\mathrm{NH}), 7.76$ (m, 12H, aromatic), 8.23 (dd, 8H, aromatic, $J=8.0 \mathrm{~Hz}$ ), 8.87 (s, 8H, $\mathrm{H}_{\beta}$-pyrrolic); ${ }^{13} \mathrm{C}-\mathrm{NMR}\left(100 \mathrm{MHz}, \mathrm{CDCl}_{3}\right) \delta \mathrm{ppm}: 120.1,126.7$, $127.7,128.8,129.1,134.6,142.2$.

\subsubsection{Synthesis of Metalloporphyrin 3a-e}

The meso-tetraphenylporphyrin $(1 \mathrm{mmol})$ and the appropriate metal salts $(5 \mathrm{mmol})$ were added to $N, N$-dimethylformamide (DMF) (5 mL) in $20 \mathrm{ml} \mathrm{CEM}$ Microwave vial. The reaction mixture heated under microwave irradiation $\left(150^{\circ} \mathrm{C}\right)$ for $15 \mathrm{~min}$ and the irradiation power was $600 \mathrm{~W}$. The reaction was monitored over time by UV-vis absorption spectrophotometry until the typical degeneracy of the $\mathrm{Q}$ bands was observed. After cooling to room temperature, the crude product mixture was washed with ice-cold distilled water $(50 \mathrm{~mL})$ and the resulting suspension was refrigerated for a few hours. Filtration of the precipitate under reduced pressure followed by washing with distilled water $(50 \mathrm{~mL})$ and drying, firstly overnight in an oven at $120^{\circ} \mathrm{C}$ and then in vacuo at room temperature, yielded the metallo-porphyrins as crystalline solids 3a-e.

\subsubsection{Iron (III) $5,10,15,20$-tetraphenylporphyrin (FeTPP) (4a)}

(0.163 mmol, $100 \mathrm{mg}$ of $\mathrm{H}_{2}$ TPP mixed with 0.815 mmol, $226 \mathrm{mg}$ in $10 \mathrm{ml} \mathrm{DMF}$ ), Reddish brown solid; yield 92\%; mp > 300 ${ }^{\circ} \mathrm{C}$; IR $\left(\mathrm{KBr}, \mathrm{cm}^{-1}\right): 2918,1478,1596,805$, 750; ${ }^{1} \mathrm{H}-\mathrm{NMR}\left(400 \mathrm{MHz}, \mathrm{CDCl}_{3}\right) \delta$ ppm: 6.6, $8.25(8 \mathrm{H}$, o-phenyl), 7.79 (4H, p-phenyl), 12.5, 13.7 (d, 8H, m-phenyl), 80.20 (s, 8H, $\mathrm{H}_{\beta}$-pyrrolic).

\subsubsection{Cobalt (II) 5,10,15,20-tetraphenylporphyrin (CuTPP) (3b)}

(0.163 mmol, $100 \mathrm{mg}$ of $\mathrm{H}_{2}$ TPP mixed with 0.815 mmol, $194 \mathrm{mg}$ in $10 \mathrm{ml} \mathrm{DMF}$ ), purple solid; yield 93\%; $\mathrm{mp}>300^{\circ} \mathrm{C}$; IR $\left(\mathrm{KBr}, \mathrm{cm}^{-1}\right)$ : 2923, 1440, 1596, 805, 750; ${ }^{1} \mathrm{H}-\mathrm{NMR}\left(400 \mathrm{MHz}, \mathrm{CDCl}_{3}\right) \delta$ ppm: 8.00 (4H, $p$-phenyl), 8.20 (8H, m-phenyl), 13.2 (8H, o-phenyl), 16.50 (s, 8H, $\mathrm{H}_{\beta}$-pyrrolic). 


\subsubsection{Nickel(II) 5,10,15,20-tetraphenylporphyrin (NiTPP) (3c)}

This complex was prepared following the procedure in reference [8]. NiTPP is a dark purple solid; yield 94\%; $\mathrm{mp}>300^{\circ} \mathrm{C}$; IR $\left(\mathrm{KBr}, \mathrm{cm}^{-1}\right): 1598,1462,1440,1384$, 1006, 793, 695; ${ }^{1} \mathrm{H}-\mathrm{NMR}\left(400 \mathrm{MHz}, \mathrm{CDCl}_{3}\right) \delta$ ppm: 7.69 (m, 12H, aromatic), 8.00 (dd, $8 \mathrm{H}$, aromatic, $J=8.0 \mathrm{~Hz}$ ), 8.74 (s, 8H, $\mathrm{H}_{\beta}$-pyrrolic).

\subsubsection{Copper (II) 5,10,15,20-tetraphenylporphyrin (CuTPP) (3d)}

(0.163 mmol, $100 \mathrm{mg}$ of $\mathrm{H}_{2}$ TPP mixed with 0.815 mmol, $199 \mathrm{mg}$ in $10 \mathrm{ml} \mathrm{DMF}$ ), Purple solid; yield 93\%; $\mathrm{mp}>300^{\circ} \mathrm{C}$; IR $\left(\mathrm{KBr}, \mathrm{cm}^{-1}\right)$ : 2918, 1440, 1597, 799, 698; ${ }^{1} \mathrm{H}-\mathrm{NMR}\left(400 \mathrm{MHz}, \mathrm{CDCl}_{3}\right) \delta \mathrm{ppm}: 7.80(\mathrm{~m}, 8 \mathrm{H}$, aromatic), 8.24 ( $p, 4 \mathrm{H}$, aromatic).

\subsubsection{Zinc(II) $5,10,15,20$-tetraphenylporphyrin (ZnTPP) (3e)}

The complex was synthesized according to reference [8]. ZnTPP is Red-purple solid; yield $96 \%$; mp > $300^{\circ} \mathrm{C}$; IR (KBr, cm$\left.{ }^{-1}\right)$ : 1596, 1482, 1439, 1339, 1002, 797, 752; ${ }^{1} \mathrm{H}-\mathrm{NMR}\left(400 \mathrm{MHz}, \mathrm{CDCl}_{3}\right) \delta \mathrm{ppm}: 7.77(\mathrm{~m}, 12 \mathrm{H}$, aromatic), 8.24 (dd, $8 \mathrm{H}$, aromatic, $\mathrm{J}=8.0 \mathrm{~Hz}$ ), 8.96 (s, $8 \mathrm{H}$, $\mathrm{H}_{\beta}$-pyrrolic).

\subsection{UV-Vis Measurements}

All the UV-Visible studies were performed using a UV-Visible spectrophotometer with $1 \mathrm{~cm}$ quartz cells in the range of $200-700 \mathrm{~nm}$ at room temperature. The stock solutions were prepared by dissolving appropriate amounts of each compound in dichloromethane to final concentrations of $10^{-6} \mathrm{M}$.

\section{Results and Discussions}

\subsection{Synthesis}

In this project, we are introducing students with microwave-assisted technique as a synthetic tool which is becoming very popular for synthesizing organic compounds in a quick and clean way. [9] The first step toward complexation started with the preparation of the free ligand. The synthesis of the $\mathrm{H}_{2}$ TPP was conducted following Gonsalves et al procedure. [10] In this method, the acid of our choice was propionic acid and nitrobenzene as an oxidant. This choice of starting materials in combination with microwave technique yielded free chlorine porphyrin precipitate as given in (eq1).

Secondly, the preparation of a porphyrin complex was a one-step process, where the ligand and appropriate metal slats were reacted using microwave technique (eq2). The metalloporphyrins 4a-e have been produced in in relatively good yield (91-96\%) (Table 1). Structures of the synthesized tetraphenylporphyrin 3 and its complexes 4a-e were confirmed on the bases of ${ }^{1} \mathrm{H} N M R$, IR and UV/Vis spectroscopy.

Table 1. Reaction time and percent yield of porphyrin $\mathrm{H}_{2}$ TPP and the metalloporphyrins 4a-e

\begin{tabular}{|c|c|c|c|}
\hline No. & Compound & Reaction time (min) & Yield \% \\
\hline $\mathbf{3}$ & $\mathrm{H}_{2}$ TPP & 5 & 68 \\
\hline $\mathbf{4 a}$ & $\mathrm{Fe}$ (II)TPP & 10 & 92 \\
\hline $\mathbf{4 b}$ & $\mathrm{Co}$ (II)TPP & 10 & 93 \\
\hline 4c & $\mathrm{Ni}$ (II)TPP & 10 & 94 \\
\hline $\mathbf{4 d}$ & $\mathrm{Cu}$ (II)TPP & 10 & 91 \\
\hline $\mathbf{4 e}$ & $\mathrm{Zn}$ (II)TPP & 10 & 96 \\
\hline
\end{tabular}<smiles>c1cc[nH]c1</smiles><smiles>[C+][CH+]</smiles><smiles>O=Cc1ccccc1</smiles>
pyrrole 1 benzaldehyde 2

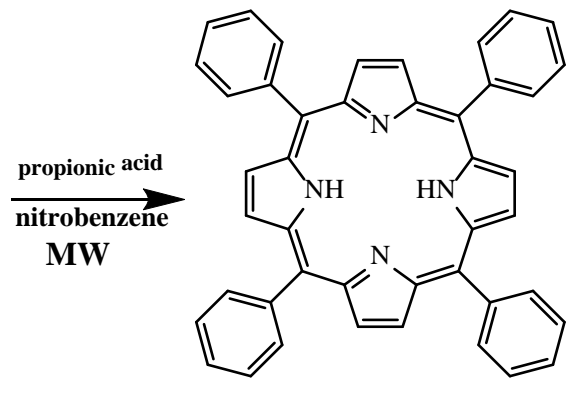

5,10,15,20-tetraphenylporphyrin 3<smiles></smiles>

5,10,15,20-tetraphen ${ }_{y} l_{p}$ or $_{p} h_{y}$ rin

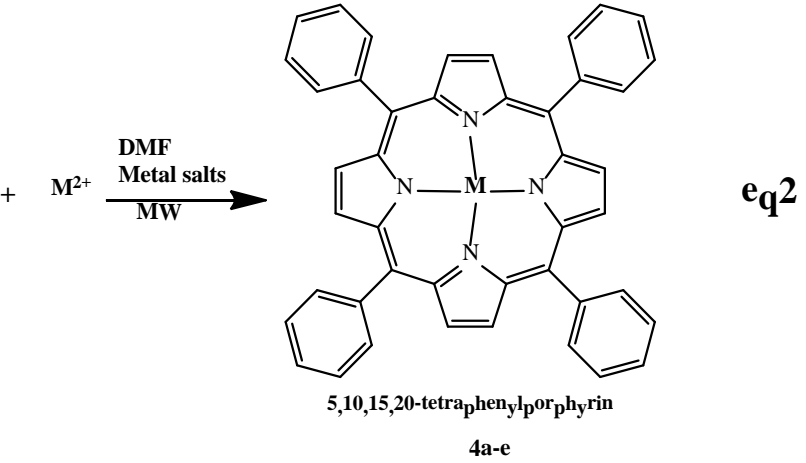

4a: $\mathrm{M}=\mathrm{Fe}$ (II); 4c: $\mathrm{M}=\mathrm{Ni}$ (II); 4b: $M=C o(I I) ; 4 d: M=C u(I I)$; 4e: $M=$ Zn (II); 
The metalloporphyrins (4a-e) were prepared by a very straightforward microwave-assisted experimental protocol, clearly demonstrating its synthetic potential when compared to other conventional synthetic methodologies used for the same purpose. The usefulness and convenience of the synthetic methods reported here arise from the use of a microwave oven, significant minimization of the reaction times, the amounts of solvents employed and the undemanding workups involved when compared with other method. For example Mamardashvili and coworkers [11] prepared Co(II)TPP conventionally by using equimolar of TPP and Co(II)salt in DMF with a reasonable yield of $72 \%$. However, they used $70 \mathrm{~mL}$ of DMF to produce $0.04 \mathrm{~g}$ of the desired Co(II) complex. Their synthesis methodology is not economic or environment-friendly to be used in the educational laboratory due to the usage of the excess of solvent.

\subsection{Structure and Spectroscopic Analysis}

\subsubsection{Structure}

Although all the MTPP in this study are almost planar $\mathrm{D}_{4 \mathrm{~h}}$ structures, some of them show some ruffling distortions $\mathrm{S}_{4}$ as depicted in Figure 1.
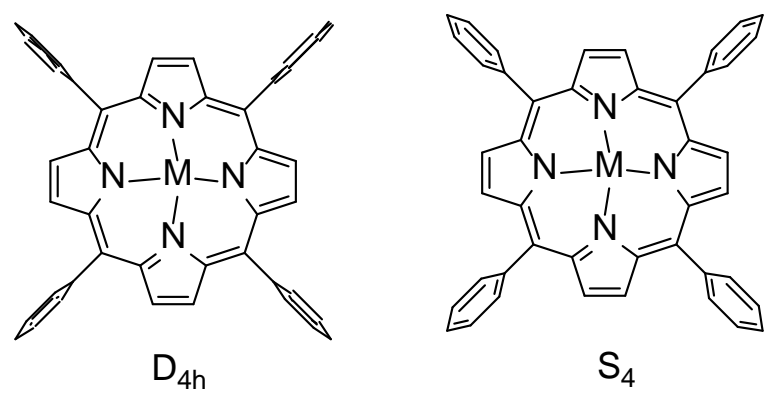

Figure 1. $D_{4} h$ structure has the phenyl ring perpendicular to the porphyrin ring. $\mathrm{S}_{4}$ structure has the phenyl ring ruffled

\subsubsection{Electronic Structure}

$\mathrm{TPP}^{2-}$ is a tetradentate strong field ligand. Therefore, we are going to assume that all of our complexes are of low pin. Consequently, the valence electrons of the first row transition metals, which are Lewis acids, complexed with the Lewis base $\mathrm{TPP}^{2-}$ should be situated in the $3 d$ orbitals of the metal ions as illustrated in Figure 2.

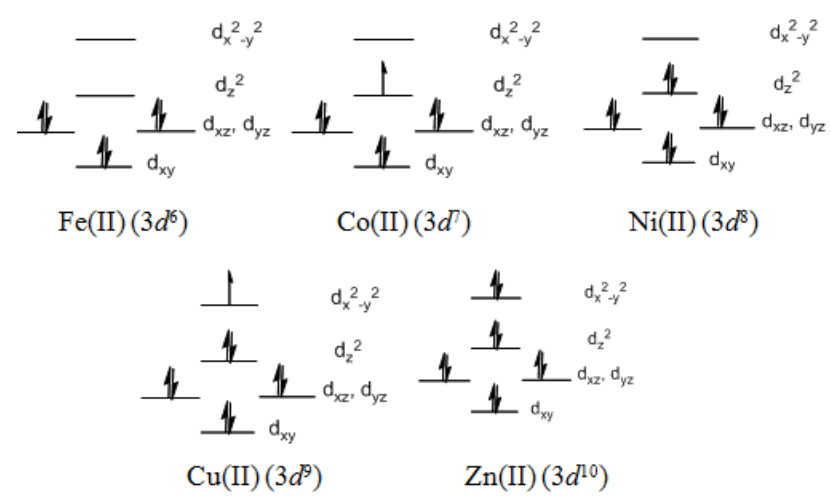

Figure 2. Metal d-orbital splitting in $\mathrm{D}_{4 \mathrm{~h}}$ and Electron. Distributions in $3 d$ low spin metal ions

\subsubsection{Frontiers Orbitals}

The energies of $3 d$ orbitals are decreasing in the direction of Fe to $\mathrm{Zn}$. The most affected orbital by this trend of the five $d$ orbitals in our complexes is $d_{x-y}^{2}{ }^{2}$ orbital. This explains why $d_{x-y}^{2}$ orbital falls into the extent of the MOs of the porphyrin ligand in NiTPP and ZnTPP. Liao and coworkers, have computed the energies of the frontiers orbitals of MTPP complexes presented in this paper. They assumed that all of these complexes have $D_{4 h}$ symmetry, therefore, the $3 d$-orbitals adopt the following symmetry: $d_{z}^{2}\left(\mathrm{a}_{1 g}\right), d_{x-y}^{2}{ }^{2}\left(\mathrm{~b}_{1 g}\right),\left(d_{x z}\right.$ and $\left.d_{\mathrm{yz}}\right)\left(\mathrm{e}_{g}\right)$, and $d_{\mathrm{xy}}$ $\left(\mathrm{b}_{2 g}\right)$. [12]

The HOMOs and LUMOs are not the same for all the complexes. Indeed, when closely examining the frontiers orbitals of our series we notice that they are different. In FeTPP the frontiers orbitals are the porphyrin ones, namely, the HOMO $\left(\mathrm{a}_{2 \mathrm{u}}\right)$ and LUMO $\left(2_{\mathrm{eg}}\left(\pi^{*}\right)\right)$ of TPP ligand and the $3 d$ of the metallic ion orbitals lay above the ring orbitals (See Figure 3). [12]
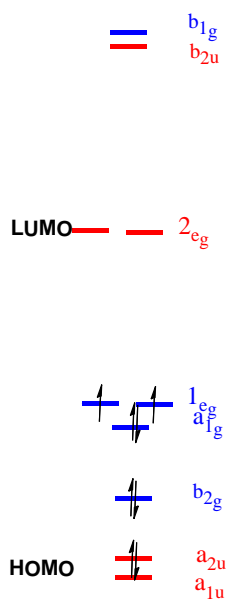

Figure 3. FeTPP Molecular Orbital Diagram according to theoretical calculations in reference [12]

In CoTPP the $d_{z}^{2}$ become lower in energy than $d_{\pi}\left(d_{x z}, d_{y z}\right)$, hence, $1 \mathrm{e}_{\mathrm{g}}\left(d_{x z}, d_{y z}\right)$ are the HOMO for the $\mathrm{Co}$ (II) complex and the LUMO is still the porphyrin's orbital set $2_{\text {eg }}\left(\pi^{*}\right)$ (See Figure 4). [12]
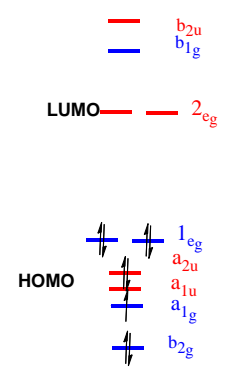

Figure 4. CoTPP Molecular Orbital Diagram according to theoretical calculations in reference [10]

The $d_{z}^{2}$ orbital in NiTPP becomes higher in energy than leg $\left(d_{x z}, d_{y z}\right)$ and therefore it is the HOMO of it. (See Figure 5). [12]

While the $d_{x-y}^{2}$ drop below the porphyrin 2eg $\left(\pi^{*}\right)$ energy and becomes the LUMO of NiTPP. The $d_{x-y}^{2}{ }^{2}$ orbital is occupied in CuTPP, thus, becomes the HOMO and the LUMO is the $2_{\text {eg }}\left(\pi^{*}\right)$ of the porphyrin (See Figure 6). [10] 


$$
\text { LUMO }-{ }^{2}{ }_{\mathrm{eg}_{1 \mathrm{~g}}}
$$

$$
\begin{gathered}
\frac{1}{4}{\frac{4}{{ }_{e g}}}^{a_{1 g}} \\
=\quad \begin{array}{l}
a_{2 u} \\
a_{1 u}
\end{array} \quad{ }^{b_{2 g}}
\end{gathered}
$$

Figure 5. NiTPP Molecular Orbital Diagram according to theoretical calculations in reference [10]

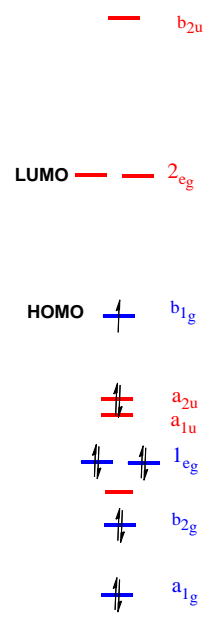

Figure 6. NiTPP Molecular Orbital Diagram according to theoretical calculations in reference [12]

Finally, Zn (II) metal ion $d$ orbitals are fully occupied and not involved in the HOMO- LUMO of the MOs of ZnTPP. Actually, the HOMO is $\mathrm{a}_{2 \mathrm{u}}$ and LUMO is $2_{\mathrm{eg}}\left(\pi^{*}\right)$ of the porphyrin (See Figure 7). [12]
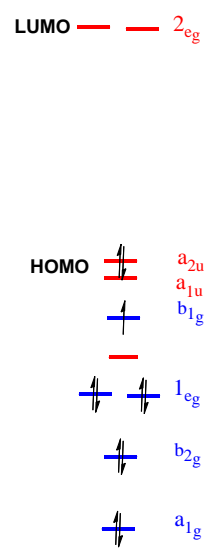

Figure 7. ZnTpp Molecular Orbital Diagram according to theoretical calculations in reference [12]
According to the above calculated values the electron configurations in the ground states of the complexes in reference [12] are: FeTPP $\left.\left\{\left(\mathrm{a}_{1 \mathrm{u}}\right)^{2}\left(\mathrm{a}_{2 \mathrm{u}}\right)^{2}\left(\mathrm{~b}_{2 \mathrm{~g}}\right)^{2}\left(\mathrm{a}_{1 \mathrm{~g}}\right)^{2}\left(1 \mathrm{e}_{\mathrm{g}}\right)^{2}\right)\right\}$, $\left.\left.\operatorname{CoTPP}\left\{\left(\mathrm{a}_{1 \mathrm{u}}\right)^{2}\left(\mathrm{a}_{2 \mathrm{u}}\right)^{2}\left(\mathrm{a}_{1 \mathrm{~g}}\right)^{1}\left(1 \mathrm{e}_{\mathrm{g}}\right)^{4}\right)\right\}, \operatorname{NiTPP}\left\{\left(\mathrm{a}_{1 \mathrm{u}}\right)^{2}\left(\mathrm{a}_{2 \mathrm{u}}\right)^{2}\left(1_{\mathrm{eg}}\right)^{4}\left(\mathrm{a}_{1 \mathrm{~g}}\right)^{2}\right)\right\}$, $\operatorname{CuTPP}\left\{\left(\mathrm{a}_{1 \mathrm{u}}\right)^{2}\left(\mathrm{a}_{2 \mathrm{u}}\right)^{2}\left(\mathrm{~b}_{1 \mathrm{~g}}\right)^{1}\right\}, \operatorname{ZnTPP}\left\{\left(\mathrm{a}_{1 \mathrm{u}}\right)^{2}\left(\mathrm{a}_{2 \mathrm{u}}\right)^{2}\right\}$.

Inspecting the frontiers orbitals of porphyrin ring shows that there are four outer molecular orbitals available to interact with the central metal ion. These orbitals are $3 \mathrm{e}$ $(\pi), 1 a_{1 u}(\pi)$ or $3 a_{2 u}(\pi)$ which are the HOMO of the ligand and $4 \mathrm{e}\left(\pi^{*}\right)$ is the LUMO of this macrocycle molecule.

According to Gouterman's model [13] the four frontier orbitals for porphyrin are $\pi\left(\mathrm{a}_{1 \mathrm{u}}\right.$ and $\left.\mathrm{a}_{2 \mathrm{u}}\right)$ and $\pi *\left(\mathrm{e}_{\mathrm{g}}\right)$ orbitals. In this model the two (HOMO's) and two (LUMO's) with their symmetry is depicted in (Figure 8). Upon energy absorption, the ligand electrons are excited from $\pi$ to $\pi^{*}$ and this phenomenon is responsible for the metalloporphyrins colors.

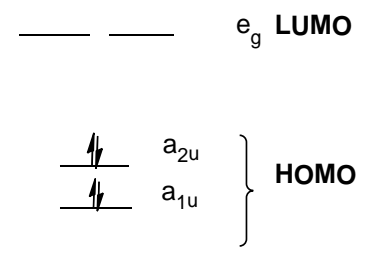

Figure 8. Gouterman's model for porphyrin

In what follow we will discuss the covalent interaction of the porphyrin frontiers orbitals with metal ions center. The $\mathrm{D}_{4 \mathrm{~h}}$ symmetry of the porphyrin does not allow for good interaction between the ring outer orbitals and the $3 d$ Fe ion. This is because the symmetries of the porphyrin outer orbitals are different than those of $d_{\pi}$ of Fe (II) in this geometry. Actually, FeTPP was found to be distorted from D4h to saddled conformation $\left(\mathrm{D}_{2 \mathrm{~d}}\right)$. [14,15] This saddled conformation enhance the covalent overlap between the metal-ligand (M-L) outer orbitals. The possible further interaction between $\mathrm{Fe}$ (II) and the porphyrin is the back- bonding from $d_{\pi}$ of $\mathrm{Fe} \rightarrow$ Porphyrin $4 \mathrm{e}\left(\pi^{*}\right)$. Generally, This M-L back-bonding is possible when the metal ion has from one to three electrons in $\left(d_{x z}, d_{y z}\right)$. [16]

\subsubsection{UV-Vis Absorption Spectra}

The absorption spectra of $\mathrm{H}_{2}$ TPP and MTPP complexes in this study were measured in dichloromethane within the spectral range $300-700 \mathrm{~nm}$. $\mathrm{H}_{2}$ TPP free base shows one intense band at $418 \mathrm{~nm}$ (Soret band $\left(\mathrm{a}_{1 \mathrm{u}}\right.$ to $\left.\mathrm{e}_{\mathrm{g}}\right)$ ) and four less intense $Q\left(a_{2 u}\right.$ to $\left.e_{g}\right)$ bands between 500 and $700 \mathrm{~nm}$ in agreement with the literature. [17] The placement of the metal ion in the cavity of the ligand results in the reduction of the $\mathrm{Q}$ bands to two peaks as listed in Table 2 . As shown in Table 2, the absorption peaks for MTPP complexes are unique for each complex and the disappearance of $647 \mathrm{~nm}$ is an indication for complexation. For the spectra please refer to Supporting Information. Other than ZnTPP, the small interaction between the metal ions and the porphyrin does not change the merit of the spectra; however, there are minimal shifts in absorptions peaks are detected.

The spectral shifts in MTPP are due to that the insertion of the divalent metal ion into TPP2- affects the $\pi-\pi^{*}$ transition. This perturbation is due to the possible interactions between the metal and ligand such as 
metal-to-ligand charge transfer (MLCT) or ligand-tometal charge (LMCT) transfer or d-d transfer.

The complexes Fe(II)TPP, Co(II)TPP, Ni(II)TPP and $\mathrm{Cu}(\mathrm{II}) \mathrm{TPP}$ peaks are shifted to shorter wavelengths due to the back bonding from metal center $d$ (electrons) to the empty ligand frontier orbitals. Because $\mathrm{Zn}$ (II) ion in Zn(II)TPP (closed-shell porphyrin) has full $d$ orbital $\left(d^{10}\right)$ it belongs to regular spectrum with no back bonding effect. In this case, $d$ orbitals are relatively low in energy and have a smaller effect on the porphyrin HOMO-LUMO energy gap.

Table 2. UV-vis data of free base porphyrins and metallated porphyrins

\begin{tabular}{|c|c|c|c|c|c|}
\hline \multirow{2}{*}{ Compound } & \multirow{2}{*}{ Soret Band } & \multicolumn{4}{|c|}{ Q Bands } \\
\cline { 2 - 6 } & & Q $_{\text {Iv }}$ & Q $_{\text {III }}$ & Q $_{\text {II }}$ & Q \\
\cline { 2 - 6 } & $\lambda_{\mathrm{nm}}$ & $\lambda_{\mathrm{nm}}$ & $\lambda_{\mathrm{nm}}$ & $\lambda_{\mathrm{nm}}$ & $\lambda_{\mathrm{nm}}$ \\
\hline $\mathrm{H}_{2}$ TPP & 418 & 516 & 551 & 589 & 645 \\
\hline FeTPP & 409 & 512 & 570 & -- & 623 \\
\hline CoTPP & 407 & -- & 527 & -- & -- \\
\hline NiTPP & 416 & -- & 523 & -- & -- \\
\hline CuTPP & 416 & -- & 539 & -- & -- \\
\hline ZnTPP & 414 & -- & 522 & 589 & -- \\
\hline
\end{tabular}

\subsubsection{IR Studies}

The range of $400-4000 \mathrm{~cm}^{-1}$ was used to record the IR absorption frequencies for $\mathrm{H}_{2}$ TPP and MTPP complexes. The IR /FTIR data are summarized in Table 3. For the spectra please refer to Supporting information. The comparison between the $\mathrm{H}_{2}$ TPP and MTPP spectra reveals the disappearance of $\mathrm{N}-\mathrm{H}$ bond stretching and bending frequencies $\left(\sim 3314 \mathrm{~cm}^{-1}\right) \delta \mathrm{N}-\mathrm{H}$ (in-planarity) and $\delta \mathrm{N}-\mathrm{H}$ (out of planarity) absorption bands $\left(964 \mathrm{~cm}^{-1}\right.$ and $798 \mathrm{~cm}^{-1}$ respectively). The disappearance of $\mathrm{N}-\mathrm{H}$ frequencies is attributed to the fact that the metallization of the porphyrin to occur, deprotonation of the two hydrogens of the ligand must take place. For the spectra please refer to Supporting Information.

\subsection{4. ${ }^{1} \mathrm{H}$ NMR Study}

${ }^{1} \mathrm{H}$ NMR spectral measurements have been conducted to verify the formation of porphyrin and its metalloporphyrins and to gain further insight toward their structures. Table 4 summarizes the characteristic ${ }^{1} \mathrm{HNMR}$ Shifts for $\mathrm{H}_{2} \mathrm{PPT}$ and MTTP complexes. The free porphyrin exhibits a singlet band for inner imino protons of the $\mathrm{H}_{2} \mathrm{TPP}$. The singlet $\mathrm{NH}$ peak (due to the rapid exchange of $-\mathrm{NH}$ protons) set at a very high field $(-2.74 \mathrm{ppm})$, since the two $\mathrm{N}-\mathrm{Hs}$ lay within the shielded cavity of the porphyrin ring. The Multiple signals which resonate at $\delta=7.74 \mathrm{ppm}$ and integrated into 12 protons are assigned to aromatic protons. The two doublets of doublet appeared at $\delta=8.22 \mathrm{ppm}$ and $\delta=8.24 \mathrm{ppm}$ are correlated to the aromatic protons $(J=4.0 \mathrm{~Hz})$ and integrated into 8 protons. The broad singlet band resonate at $\delta=8.87 \mathrm{ppm}$ due to $\beta$ - protons of pyrrole ring and integrated into 8 protons. Metalloporphyrins ${ }^{1} \mathrm{H}-\mathrm{NMR}$ spectra showed the disappearance of the $\mathrm{NH}$ peak at around -2.74 ppm which designates the formation of metalloporphyrins. Crystalline phase study by $\mathrm{Hu} \mathrm{C}$. and coworkers [14] showed that Fe(II)TPP has a very saddled symmetry. This explains why Fe(II) in TPP has two unpaired electrons in $d_{\mathrm{x} 2-\mathrm{y} 2}$ and not as we predicted (see Figure 2). This confirms the theoretical results. This structure conformation was also seen in Co (II)TPP. The distinguishing features of paramagnetic complexes of $\mathrm{Co}$ (II) and $\mathrm{Cu}$ (II) ions are that all the proton signals are shifted to the downfield with the broadening of the resonance signals. $\mathrm{Cu}(\mathrm{II}) \mathrm{TPP}$ has the electronic configuration of $\left(d_{\mathrm{xy}}\right)^{2}\left(d_{\mathrm{xz}}, d_{\mathrm{yz}}\right)^{4}\left(d_{\mathrm{z}}^{2}\right)^{3}\left(d_{\mathrm{x}-\mathrm{y}}^{2}\right)^{1}$. [18] The location of the unpaired electron in the plane of the porphyrin plane allows for spin delocalization through $\sigma$ bond especially for the $\beta$-pyrrole. This delocalization is responsible for the extreme broadening seen for the $\beta$ pyrrole signals in this complex. [19]

Table 3. IR/FIR data of free base porphyrins and metalloporphyrins

\begin{tabular}{|c|c|c|c|c|c|c|}
\hline \multirow{2}{*}{ Functional Group } & \multicolumn{6}{|c|}{ Wavenumber $\left(\mathrm{cm}^{-1}\right)$} \\
\cline { 2 - 7 } & $\mathrm{H}_{2}$ TPP & Zn(II)TPP & Ni(II)TPP & Fe(II)TPP & Cu(II)TPP & Co(II)TPP \\
\hline$v[\mathrm{NH}]$ & 3314 & - & - & - & - & - \\
\hline$v[=\mathrm{C}-\mathrm{H}]$ & 2923 & 2923 & 2922 & 2923 & 2918 & 2923 \\
\hline$v[\mathrm{C}=\mathrm{N}]$ & 1490 & 1339 & 1384 & 1384 & 1440 & 1440 \\
\hline$v[\mathrm{C}=\mathrm{C}]$ & 1593 & 1596 & 1598 & 1596 & 1597 & 1596 \\
\hline$\delta[\mathrm{C}-\mathrm{H}]$ & 798,698 & 797,752 & 793,695 & 798,698 & 799,698 & 805,750 \\
\hline$\delta[\mathrm{NH}]$ & 964 & - & - & - & - & - \\
\hline
\end{tabular}

Table 4. ${ }^{1} \mathrm{H}$ NMR chemical shifts ( $\delta$ in ppm) taken in $\mathrm{CDCl}_{3}$ solution at $298 \mathrm{~K}$

\begin{tabular}{|c|c|c|c|c|c|}
\hline \multirow{2}{*}{ Complexes } & \multirow{2}{*}{-NH } & \multirow{2}{*}{ Pyrrole } & \multicolumn{3}{|c|}{ Meso } \\
\hline & & & Ortho & Meta & Para \\
\hline $\mathbf{H}_{2}$ TPP & -2.74 & 8.87 & 8.23 & 7.76 & 7.76 \\
\hline Fe(II)TPP & - & 13.45 & 7.55 & 7.79 & 7.66 \\
\hline Co(II)TPP & - & 16.50 & 13.20 & 8.20 & 8.00 \\
\hline Ni(II)TPP & - & 8.74 & 8.00 & 7.69 & 7.69 \\
\hline Cu(II)TPP & - & $\mathrm{a}$ & $\mathrm{a}$ & 7.80 & 8.24 \\
\hline Zn(II)TPP & - & 8.96 & 8.24 & 7.77 & 7.77 \\
\hline
\end{tabular}

a: Too broad to detect.

For the spectra please refer to Supporting Information. 


\section{Conclusion}

Our conclusion for the above work can be summarized as follow:

1. Synthesis using microwave techniques can be used in educational laboratories to prepare some compounds in a fast and clean way. Multi-mode microwave that can be used to carry several reactions under the same conditions at the same time can be very advantageous in educational laboratories.

2. UV-Vis, IR/FTIR and ${ }^{1}$ HNMR spectroscopies are powerful tools in detecting the complexation between the porphyrin ligand and metal ion and to check their purities.

3. ${ }^{1} \mathrm{H}$ NMR spectroscopy is a reasonable tool that can be utilized to gain some knowledge about the spin of the metal ion in metalloporphyrin complexes.

4. Correlating the results of theoretical studies such as the calculations of orbitals energies in the ground state with the experimental data gives deeper understanding of the electronic structure of the complexes in this study.

\section{Acknowledgments}

The authors would like to sincerely thank the undergraduate students that help in repeating the synthesis and spectroscopic measurements of this project. Our appreciations go to Abdalla Abdelhamid, Aymane Bennasser, Loai Omar, Yassin Ibrahim, Ruba Abdullah Al-Ajeil.

\section{References}

[1] Auwarter W., E.D., Klappenberger F., Barth G. V., Nature Chemistry, 2017. 7: p. 105-120.

[2] Kadish K.M., S.K.M., Guilard R., Bioinorganic and Bioorganic Chemistry. In The Porphyrin Handbook. Vol. 11. 2003, San Diego, CA, USA. 1-277.
[3] Kadish K.M., S.K.M., Guilard R., Biochemistry and Binding: Activation of Small Molecules. In The Porphyrin Handbook. Vol. 4. San Diego, CA, USA.

[4] Imran M., R.M., Qureshi A. K., Khan M. A., Tariq M., Biosensors, 2018. 8: p. 95.

[5] Chou J., K.M.E., Nalwa H. S, Rakow N. A., Journal of Porphyrins and Phthalocyanines, 2000. 4(4): p. 407-413.

[6] Nagarajan S., B.F.F., Samuelson L., Kumar J., Nagarajan R., Metalloporphyrin based Biomimetic Catalysts for Materials Synthesis and Biosensing. Biomaterials, 2010. 1054: p. 221-242.

[7] Alexandre F-R, D.L., Frère S, Testard A and Thiéry V., Mol. Diversity 2003. 7: p. 237-280

[8] Neyadi, S.S.A., Alzamly, A., Al-Hemyari, A., Tahir, I. M., Al-Meqbali, S., Ahmad, M. A. A., \& Bufaroosha, M., An Undergraduate Experiment Using Microwave-Assisted Synthesis of Metalloporphyrins: Characterization and Spectroscopic Investigations. World Journal of Chemical Education, 2019.

[9] Rocha Gonsalves, A.M.d.A., Varejão, J. M. T. B., Pereira, M. Some New Aspects Related to the Synthesis of meso-Substituted Porphyrins. Journal of Heterocyclic Chemistry, 1991. 28: p. 635-640.

[10] Rocha Gonsalves, A.M.d.A.V., J. M. T. B.; Pereira, M. M. , J. Heterocyclic Chem., 1991. 28: p. 286.

[11] Mamardashvili, G.M., Simonova, O. R., Chizhova, N. V., \& Mamardashvili, N. Zh., Influence of the Coordination Surrounding of Co(II)- and Co(III)-Tetraphenylporphyrins on Their Destruction Processes in the Presence of Organic Peroxides. Russian Journal of General Chemistry, 2018. 88(6): p. 1154-1163.

[12] Liao, M.S., Scheiner, S., J. Chem. Phys, 2002. 117(1): p. 205-219.

[13] Gouterman M., Dolphin D., Ed., The Porphyrins. Academic, N. Y., 1978. 3: p. 1.

[14] Hu C., N.B.C., Schulz C. E., and Scheidt W. R., Four-Coordinate Iron(II) Porphyrinates: Electronic Configuration Change by Intermolecular Interaction. Inorg Chem. 2007. 46(3): p. 619-621.

[15] R. B. King, R.H.C., C. M. Lukehart, D. A. Atwood, \& R. A. Scott (Eds.), Iron Porphyrin Chemistry, in Encyclopedia of Inorganic Chemistry. 2006, Walker, F. A., \& Simonis. p. 2390-2521.

[16] F. Ann Walker, U.S., Iron Porphyrin Chemistry in in Encyclopedia of Inorganic Chemistry, R.B. King, Editor. 2005, John Wiley \& Sons: Ltd, Chichester, p. 2390-2521.

[17] Sun Z.C., S.Y.B., Zhou Y., Song X.F., Li, K., Synthesis, Characterization and Spectral Properties of Substituted Tetraphenylporphyrin Iron Chloride Complexes. Molecules, 2011. 16(4): p. 2960-2970.

[18] Walker, F.A.W., NMR and EPR spectroscopy of Paramagnetic Metalloporphyrins and Heme Proteins. Handbook of Porphyrin Science. Vol. 6. 2010.

[19] Walker, F.A., Inorg. Chem., 2003. 42: p. 4526-4544. 